\title{
Compiuter technologies assist potential energy with experiments
}

\author{
Alion Alizoti ${ }^{*}$, Floran Vila ${ }^{\text {a }}$ Zenun Mulaj ${ }^{\text {a }}$ Polikron Dhoqina ${ }^{\text {a }}$ \\ ${ }^{a}$ Department of Physics, Faculty of Natural Sciences, University of Tirana, Bvd. Zogu I, Tirana, Albania \\ E-mail: alion.alizoti@fshn.edu.al; $\quad$ alion.alizoti@yahoo.com
}

\begin{abstract}
Energy is an important physical quantity to study and reconstruct nature at our own leisure. Implementations of new tendencies in Physics show that energy, and other physical quantities, need careful examinations before being applied. Following international and national recommendations, our present work focused on several research studies concerning potential energy. A simple experiment was developed to verify the conservation of energy. At the end, the participants were convinced that it is really difficult to achieve the conservation of energy to its perfect form. They also ended with some intriguing conclusions, similar to the research studies this activity referred to.
\end{abstract}

\section{Introduction.}

For many years now, Albania has been undergoing great changes. Among others, education is changing too. Along with other countries, Albania has applied a new educational system, nine years of primary education and three years of secondary education [1. A. ALIZOTI, F. VILA, Z. MULAJ, P. DHOQINA, 2013]. Following international and national recommendations, new curriculums are developed. Natural sciences are also facing with the demands for new curriculums [2. A. ALIZOTI, F. VILA, Z. MULAJ, 2014]. As challenges of the new century have expanded the range of tasks universities are facing, education should motivate students to social change and innovative practices [3. Iryna Soldatenko, 2020]. To satisfy the need for appropriate tools for their socio - psychological and technological support, new tendencies in Physics, and other natural sciences, are being implemented to help teachers and students. Theories, experiments and practical applications are considered to be the best educational methods to achieve physical wisdom [4. A. ALIZOTI, F. VILA, Z. MULAJ, P. DHOQINA, 2016].

As an example, in mechanics, advanced research is focusing on nonlinear vibrations of a mass connected to a cable, and methods are being aplied to solve complex nonlinear equations. Under gravitational conditions, Compiuter softares and harmonic balancing methods are well used to investigate the influence of different parameters in nonlinear vibration under nearly balanced gravitational conditions [5. Masoud Rahmani, Ionut-Cristian SCURTU, Amin Moslemi Petrudi, 2020]. Also, in mechanics, practical models 
are considered to analyse the lifting operations of a boom crane and, thus, compiuter designs and mathematical formulaes are utilised to explain the lifting mechanism of the crane [6. C. Fratila, T. Axinte, R. C. Cojocaru, C. Berescu, I. C. Scurtu, 2020]. Compiuters and softares are used in electricity too, to simulate, analyze and better understand the power supplies [7. Cristian Victor Lungu, Bogdan Hnatiuc, 2020].

Physics has developed many physical quantities, concepts and laws to study nature. Energy is one of this quantities widely used to explain natural phenomenon and predict the behavior of physical systems. Being so popular, energy and its laws need careful examination before applied. Researchers are being worried with the idea that people may misunderstand the energy and its universal applications [8. MATT STRASSLER, 2012]. Studies show that students may get confused with work and energy, or their equations [9. JOHN W. JEWETT JR, 2008].

To support this kind of research studies, a free falling experiment was developed. Our master students of physics teaching participated in the experiment. The participants were divided into three groups, according to team work methods. Each group was composed of five or six students.

\section{Study Theory.}

The Sensor - Interface - Computer System based on Logger Pro, Vernier Software \& Technology, has been applied to study the free fall of a spherical body [10. Logger Pro, Vernier Software \& Technology]. This system is used to capture the time interval that the falling body takes to go through the Photo gate sensor, figure 1 .
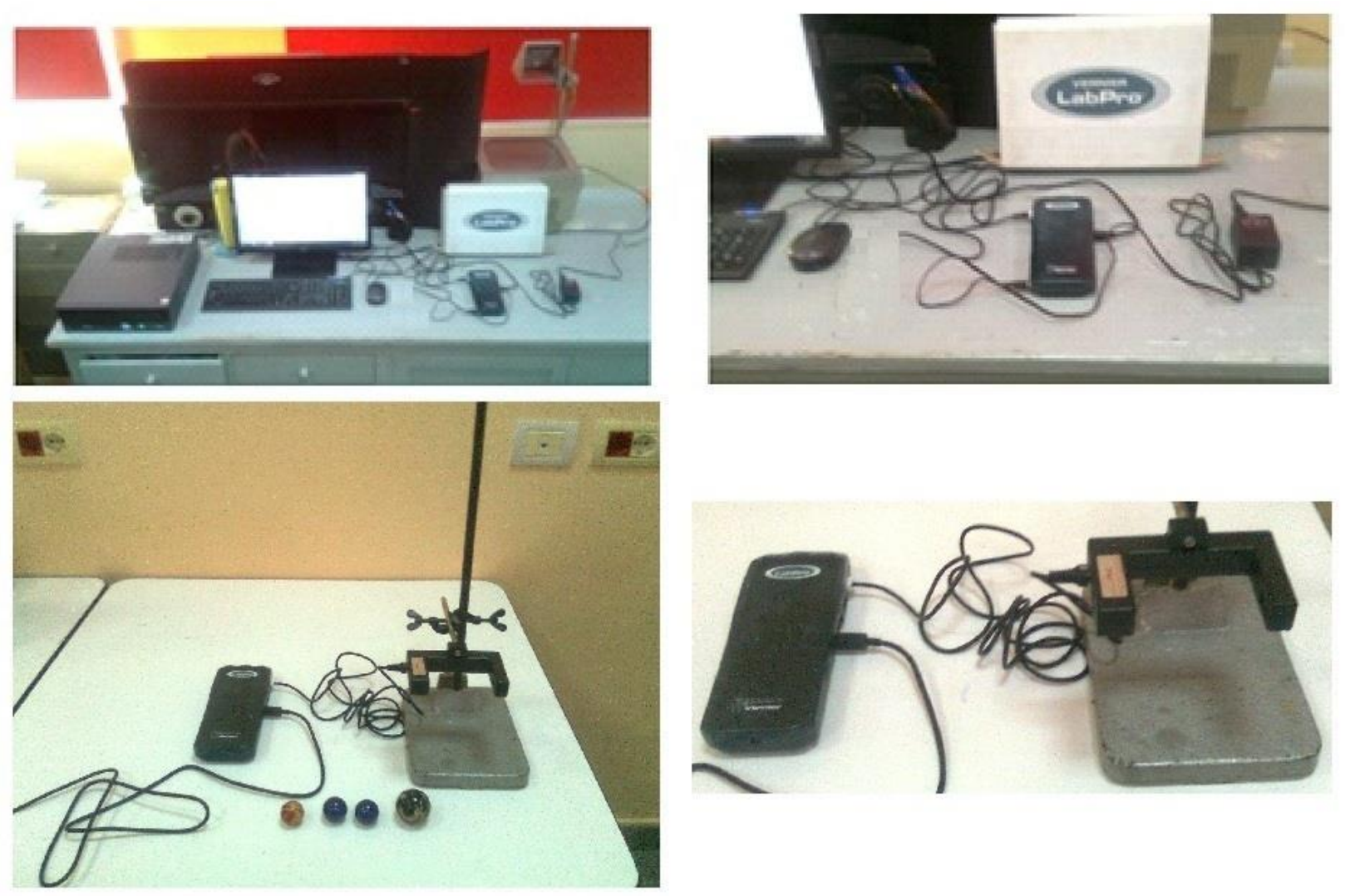

Figure 1 
From experimental data the instantaneous velocity of the free falling body can be calculated.

$$
v=\frac{D}{t}
$$

$\mathrm{D}$ is the diameter of the spherical body, and $\mathrm{t}$ is the time interval to fall free through the photo gate.

Theoretically, a free falling body should obey to the conservation of mechanical energy.

$$
\text { Ep }=E k \quad P h=E k \quad m g h=m \frac{v^{2}}{2}
$$

Theoretical and experimental explanations are provided in Table 1, according to American standards of physics curriculum and high schools.

\begin{tabular}{|c|c|c|c|}
\hline Physical Quantity & Symbol & Relationship & Concept - Meaning \\
\hline Potential Energy & Ep & $\mathrm{Ep}=\mathrm{mgh}$ & Energy of the body, initially at rest at height $h$ \\
\hline Kinetic Energy & Ek & $\mathrm{Ek}=\mathrm{m} \frac{\mathrm{v}^{2}}{2}$ & Energy of the moving body, leaving the photo gate. \\
\hline Weight & $\mathrm{P}$ & $\mathrm{P}=\mathrm{mg}$ & $\begin{array}{l}\text { Weight of the body, calculated by mass and the } g \\
\text { constant. } \\
g=10 \mathrm{~N} / \mathrm{kg} \text { in primary education } \\
\mathrm{g}=9.8 \mathrm{~N} / \mathrm{kg} \text { in secondary and higher education }\end{array}$ \\
\hline Mass & $\mathrm{m}$ & & $\begin{array}{l}\text { Mass of the body, measured under universal } \\
\text { conditions on Earth lab. }\end{array}$ \\
\hline Height & $\mathrm{h}$ & & Height of the body, at rest above the photo gate. \\
\hline Velocity & $\mathrm{V}$ & & Falling velocity of the body, leaving the photo gate. \\
\hline
\end{tabular}

Table 1.

\section{Method.}

Logger Pro Interface and Photo Gate are used to measure and calculate the time interval the falling body takes to go through the Photo Gate Sensor on the ground level, figure 2. 

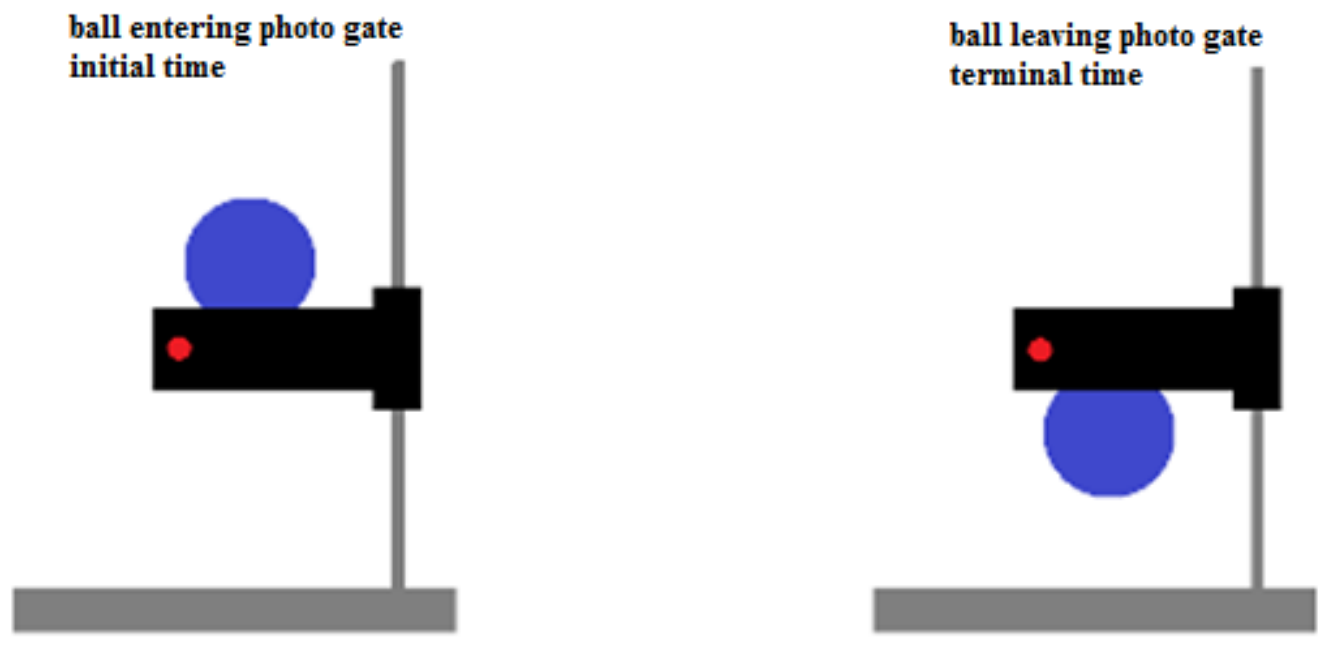

Figure 2

Data of these measurements are used to calculate velocity. Calculations were also made to strictly verify the conservation of energy. The results are shown in Table 2, confirming that conservation of energy is not easily achieved.

Table 2. Report Data

\begin{tabular}{|c|c|}
\hline Group & Verify Data \\
\hline First & $9.75 \quad(9.8)$ \\
\hline Second & $9.86 \quad(9.8)$ \\
\hline Third & $9.69 \quad(9.8)$ \\
\hline Common & Almost \\
\hline
\end{tabular}

To avoid confusions, students were advised to open ended discussions. From discussions, they reached some new insight concerning the practical applications of physical laws. Student also came to some intriguing conclusions to follow:

1. Accomplish more accurate measurements and calculus.

2. Introduce and properly use inertial mass, instead of rest mass only:

$$
\boldsymbol{m} \boldsymbol{g h}=\boldsymbol{m}^{\prime} \frac{v^{2}}{2}
$$

3. Bring balance to energy equations by considering Loss or Gain variables.

$$
E \boldsymbol{p}=\boldsymbol{k} E \boldsymbol{k}
$$

4. Reconsider weight and mass.

$$
\boldsymbol{P}=\boldsymbol{m} \boldsymbol{g}
$$

5. Pay attention to energy applications in other physical subjects as well. 


\section{Conclusions}

Education in Albania is evolving to other structures. New curriculums are developing, considering contemporary tendencies, institutional recommendations and research studies. To satisfy the demands for perfecting methodologies through precision measurements, verifying experiments are necessary [11. KOPONEN T. I. \& Mäntylä T., 2010]. In the case of potential energy, a free falling experiment has been carried out by students. Data collection and analyzes helped students with this activity. Experimental data confirmed that conservation of energy is difficult to achieve. Open ended discussions enabled students to work on several options regarding energy. Whether potential energy is real or not, a body should be lifted up to certain height in order to fall free [12. EUGENE HECHT, 2003]. Whether kinetic energy is real or not, a body gains speed while falling free. To establish a good relationship between potential energy and kinetic energy, our students worked with conservation of energy. This application helped students to better understand the obsolete relationship between mass and energy [13. RALPH BAIERLEIN, 2007]. In addition to science, this activity was also aiming to help master students with their future contributions to solve learning problems in energy teaching or learning [14. MARISA MICHELINI, ALBERTO STEFANEL, 2010], [15. PAOLA HERON, MARISA MICHELINI, ALBERTO STEFANEL, 2009].

Apart from science, applications of new technologies in education are highly regarded as efficient tools of assistive technology (AT) with students with Autism Spectrum disorder [16. Abdullah Alanazi, 2020]. Furthermore, compiuter models are succefully being applied to predict the future course of an epidemic and take time - tested measures to control the outbreak and spread over [17. S. Fernandez - Erana, L. Fernandez - Erana, M. Fernandez -Guasti, 2020], [18. Uzma Aamir Jilani, Ishrat Rahman, Syed Aamir Jilani, 2020].

\section{References}

[1]. A. ALIZOTI, F. VILA, Z. MULAJ, P. DHOQINA: Contemporary Tendencies in Physics Education, RENS 2013 International Conference, BENA and University of Shkodra, Luigj Gurakuqi, Albania, 2013.

[2]. A. ALIZOTI, F. VILA, Z. MULAJ: Methodologies in Physics Education, ICRAE 2014 International Conference, University of Shkodra, Luigj Gurakuqi, Albania, 2014.

[3]. Iryna Soldatenko, Communication technologies to encourage innovative activities engagement in students, Technium Vol. 2, Issue 7 pp.201-208 (2020) ISSN: 2668-778X www.techniumscience.com

[4]. A. ALIZOTI, F. VILA, Z. MULAJ, P. DHOQINA: Physics Subject Matter in Secondary Education, JEPE 2016.

[5]. Masoud Rahmani, Ionut-Cristian SCURTU, Amin Moslemi Petrudi, Analytical and Dynamic study of Pulled Mass Nonlinear Vibration by Two Cables using Newton's Harmonic Balance Method, Technium Vol. 2, Issue 2, pp. 79-86, (2020) ISSN: 2668-778X www.techniumscience.com

[6]. C. Fratila, T. Axinte, R. C. Cojocaru, C. Berescu, I. C. Scurtu, The study of the lifting mechanism of the crane arm to a barge, Technium Vol. 2, pp. 91-96, (2020) ISSN: 2668-778X www.techniumscience.com

[7]. Cristian Victor Lungu, Bogdan Hnatiuc, Simulation of power supplies used for nonlinear electrical discharges, Technium Vol. 2, pp. 79-84, (2020 ISSN: 2668-778X www.techniumscience.com 
[8]. MATT STRASSLER: Matter and Energy: A False Dichotonomy, April 12, 2012, https://profmattstrassler.com/articles-and-posts/particle-physics-basics/mass-energy-matteretc/matter-and-energy-a-false-dichotomy/

[9]. JOHN W. JEWETT JR: Energy and The Confused Student I: Work, The Physics Teacher, Vol. 46, January 2008.

[10]. Logger Pro, Vernier Software \& Technology, http://www.vernier.com/products/software/lp/

[11]. KOPONEN T. I. \& Mäntylä T.: Generative role of experiments in physics and in teaching physics: A suggestion for epistemological reconstruction, Department of Physical Sciences, University of Helsinki, Finland, 2010.

[12]. EUGENE HECHT: An Historico-Critical Account of Potential Energy: Is PE Really real?, The Physics Teacher, Vol. 41, November 2003.

[13]. RALPH BAIERLEIN: Does nature converts mass into energy?, American Journal of Physics, Vol. 75, No. 4, April 2007.

[14]. MARISA MICHELINI, ALBERTO STEFANEL: Approaches and learning problems in energy teaching/learning: an overview, International Conference GIREP - ICPE - MPTL 2010, Universite de Reims Champagne Ardenne, Reims 22 - 27 August 2010.

[15]. PAOLA HERON, MARISA MICHELINI, ALBERTO STEFANEL: Teaching and learning the concept of energy at 14 years old, Frontiers in Science Education Conference, EMU, Famagusta Cyprus, 2009.

[16]. Abdullah Alanazi: Special Education Teachers' Knowledge of Using Assistive Technology with Students with Autism Spectrum Disorder Technium, Vol. 2, Issue 7 pp.54-63 (2020) ISSN: 2668778X www.techniumscience.com

[17]. S. Fernandez - Erana, L. Fernandez - Erana, M. Fernandez -Guasti, COVID-19 dynamical evolution prediction in Mexico, decision making and social implementation: mid/low income countries study, Technium Vol. 2, Issue 7 pp.107-117 (2020) ISSN: 2668-778X www.techniumscience.com

[18]. Uzma Aamir Jilani, Ishrat Rahman, Syed Aamir Jilani, Management Prospects for COVID-19: A Review, Technium Vol. 2, Issue 7 pp.118-127 (2020) ISSN: 2668-778X www.techniumscience.com 